\title{
PSYCHOLOGICAL AND PEDAGOGICAL SUPPORT FOR THE DEVELOPMENT OF CREATIVE CAPABILITIES IN THE CHILDHOOD PERIOD
}

\section{Bila I. N.}

\section{INTRODUCTION}

The researcher of children's creativity E.V. Subotskyi stated that "the creative, intellectual and moral capabilities of a child are inexhaustible. It is unlikely that today they are used for one hundredth part. To reveal and realize them is an incredibly difficult task. In other words, we live above the deposits of precious "minerals" of the psychics, most often not even suspecting them" . It is important to find out the "personal code" of each child and select the "keys" to the development of his or her talents precisely during their formation.

The raised problem of identifying the abilities of children in preschool age and providing favourable conditions for personal formation, creative self-realization of a child, the formation of an active-cognitive, creative attitude to the real world in a pre-schooler, the ability to orientate successfully in a wide variety of objects and phenomena, arming with methods of creative cognitive activity can be solved by analysing effective diagnostic tools and activating creative abilities at the childhood stage.

The decisive step in solving the tasks set may be the construction of a theoretical and structural model of the development of capabilities, which takes into account the integrative, multidimensional structure of capabilities and the laws of their ontogenesis, which are manifested in the individual characteristics of the course of mental processes and personality formations in certain types of activities. The model is a guideline for determining the criteria for assessing the development of various types of capabilities, their growth vector in the developing space conditions.

\footnotetext{
${ }^{1}$ Subbotskiy S.V. The child opens the world / S.V. Subbotskiy - M.: Prosveshcheniye, 1991. - 207 p.
} 


\section{A structural model for studying the basic characteristics of a child's capabilities}

Let us emphasize that childhood is a period of formation of a child's psychics, the emergence of particularly favourable prerequisites for the flowering of his or her individual creative capabilities and giftedness, etc. That is why it is so important to ensure at this age the diversified development of all the talents and possibilities for manifesting the child's personality. This is possible only if adults take into account the child's individual peculiarities, characteristics and favourable conditions for the formation and development of children's talents.

Well-known psychologists and teachers (L.S. Vygotskyi, V.A. Krutetskyi, V.T. Kudryavtsev, O.I. Kulchytska, M.M. Poddyakov, B.M. Teplov and others) proved that capabilities are vividly manifested in the childhood and gradually develop in the process of specially organized training. The construction of a model, a project-study scheme, the development of capabilities and the awareness of adults raising children about the specifics and patterns of their manifestation will accelerate the success of the growth of the capabilities, the formation of a creative and harmonious personality.

We chose the ideas of scientists as the theoretical basis for the development of the model (P.Ya. Galperin, D.B. Elkonin, V.V. Davydov, O.M. Leontyev, S.L. Rubinshtein, B.M. Teplov and others) regarding the dynamic essence of the capabilities, the determining factors of their development, in particular, upbringing and training and interaction with the social environment. The human's capabilities, in their opinion, are the internal conditions for his development, which are formed under the influence of the external conditions in the process of interaction with the world. "The practical limits of the development of the capabilities are determined only by such factors as the length of a human life, the conditions of this life, the methods of education and training, etc., but are not at all embedded in the capabilities themselves. It is enough to improve the methods of education and training so that the limits of the development of the capabilities immediately expand" (B.M. Teplov, 1961). According to S.L. Rubinstein, the development of capabilities is done in a spiral: "... the realization of a capability, which represents a capability of one level, opens up new possibilities for the further development of the capabilities of a higher level. The composition of each capability which 
makes a person capable of performing certain activities always includes some operations or modes of action by which this activity is carried out. No capability is an actual, real capability, until it organically absorbs the system of relevant socially developed operations (S.L. Rubinstein, 1960) ${ }^{2}$.

O.M. Leontyev, developing the ideas of L.S. Vygotskyi, justifies the "historical inheritance of capabilities": instruments of production and products of labour are the embodiment of human capabilities. He also claims that a person has only one ability - the ability to develop, and abilities are formed in the process of assimilation by each generation of people of what was created by previous generations, thereby historically inheriting the capabilities of previous generations. This process in each generation opens up new opportunities for their development compared to previous generations ${ }^{3}$.

In the composition of capabilities, the motivational, value-based, and cognitive components are important. Motivation, interest, individual values and knowledge determine the qualitative specificity of capabilities, the specificity of solving cognitive tasks by an individual depends on them.

Each type of creative activity is characterized by a psychologically unique composition of capabilities, individual differences, manifested both in the general level of giftedness and in the qualitative originality of individual cognitive processes, in their structural interrelation.

According to V.O. Krutetskyi, the integrative nature of capabilities manifests itself in the individual characteristics of the course of mental processes (attention, perception, imagination, thinking, memory) and personality formations (orientation of relationships and emotionalvolitional elements) in certain types of activity. Therefore, capabilities can be classified by psychological, personal criteria such as: sensorimotor, perceptual, mnemonic, imaginative, thinking, communicative, motivational, emotional and volitional, etc., as well as by the criteria of attribution to a specific subject area - scientific (humanitarian, linguistic, mathematical, engineering), artistic (literary, musical, visual) and more. Capabilities are also subdivided into common ones that are found in most activities (mental, physical, academic) and special, narrow, limited by

\footnotetext{
${ }^{2}$ Rubinstein S. L. The problem of capabilities and questions of psychological theory // Psychology of individual differences / ed. by Yu.B. Gippenreiter, V.Ya. Romanova. - 3-rd ed., revised and accomplished - M.: AST: Astrel, 2008. - P. 47-54.

${ }^{3}$ Losyeva A. A. Psychological diagnosis of giftedness: a textbook for high schools / A.A. Losyeva. - M.: Academic Project: Triksta, 2004. - 176 p.
} 
subjects of these activities (technical, operator, pedagogical, managerial, musical, literary, mathematical $)^{4}$.

V.D. Shadrikov proposed the division of capabilities into creative and performing, which reflects the essential differences between the creative and conservative personality type. The author emphasizes that normative (performing) capabilities are a necessary stage in the development of others, which should provide the conditions for a qualitative leap from performance to creativity ${ }^{5}$.

Therefore, capabilities are developed on the basis of integration components, personality traits, in conditions of direct interaction of an individual with society. The interconnection of these components, external and internal conditions for the development of capabilities is the starting point and theoretical basis for solving the fundamental debatable issues of the theory of capabilities, developing a model and experimental tools for their analysis.

Currently the presented analysis of the scientific theories gives us grounds for the construction of such a theoretical and structural model of development of capabilities (Fig. 1), which takes into account the integrative, multidimensional structure of capabilities and patterns of their ontogenesis, which are manifested in individual features of the course of mental processes (attention, perception, imagination, thinking, memory) and personal formations (the focus of attitude, emotional and value-based, volitional elements) in certain kinds of activities. The constructed model is the basis for determining the criteria for assessing the development of different types of capabilities and their growth vector.

It should be emphasized that the most effective diagnostic method of studying the capabilities at preschool age is the observation of a child in various activities and recording life observations. The advantages of the observation method are that it takes place in natural, child-friendly surroundings, at home, in an educational establishment where the effects of the restrictions imposed by standardized tests are unaffected.

The most efficient method of studying interests, inclinations and abilities, from an early age, is observation. During the observation of the child's play, his or her behaviour in different activities, an adult observes

\footnotetext{
${ }_{5}^{4}$ Platonov K.K. Problems of capabilities / K.K. Platonov. - M., Nauka, 1972. - 312 p.

Shadrikov V.D. Psychology of capabilities // Psychology of individual differences / ed. by Yu.B. Gippenreiter, V.Ya. Romanova. - 3-rd ed., revised. and accomplished. - M.: AST: Astrel, 2008. p. 64-79. - (Reading book on Psychology).
} 
the individual features of capabilities manifestation, generally determines the type of activity that the child prefers in the situation of choice, that is, he allots most of the time and enjoys the greatest pleasure, etc.

A successful attempt is for an adult to keep a creative diary of a child, where the results of observations of his or her creative activity are noted, interests and capabilities are recorded in the course of games and selfactivity, as well as the results and achievements of his or her successful productive activity.

Widely used in development work are the data obtained in the course of studying the products of children's activities, conducting conversations, and using the methodology of incomplete sentences, etc. So, for example, the child is suggested to continue a saying like: "Most of all I like to do...", "In the future I dream of becoming...", "I want the wizard...", etc.

It will be appropriate to use practical methods of studying subjective preferences, which have been known in the East since ancient times. So, the intuitive subjectivization of a baby's choice can be observed if at the age of 1 to 3 years you put in front of him a book, money, a hammer and a weapon. Left alone, the child makes a choice that is made so far unconsciously, but quite projectively. For example:

- The child chooses the object of work - he wants to do everything himself. It can be predicted that his leading quality in the future will be hard work;

- The child chose a weapon - he likes to control, play war. A child will grow into a leader who has a strongly pronounced desire to protect the weak;

- The child preferred the book. The kid showed a desire to engage in scientific or literary activities, and for the time being enjoys listening and reading. For such children, the most important thing is to understand the content. Their main feature is honesty;

- A small hand which reached for the bill reveals the character of a person inclined to engage in trade, business and economic activity. The main feature is generosity and a simultaneous desire to be rich ${ }^{6}$.

The episodes from the life of children from the tales of parents, educators, and other adults involved in the upbringing can provide fairly comprehensive information about the child's developmental history and the interests of the child. All this is of particular importance given that the traditional testing conditions do not give researchers sufficient time to

\footnotetext{
${ }^{6}$ Bila I.M. Psychology of children's creativity / I.M. Bila. - Kyiv., Phoenix, 2014. -200 p.
} 
monitor the child, and this forces them to focus on the results of the implementation of specially proposed tasks. The observations are also valuable because they help to identify especially rare capabilities that may be missed during the examination of the child. If the child is monitored systematically for a certain period, the results make up a map (portrait) of the child's development, which is difficult to obtain with the help of tests.

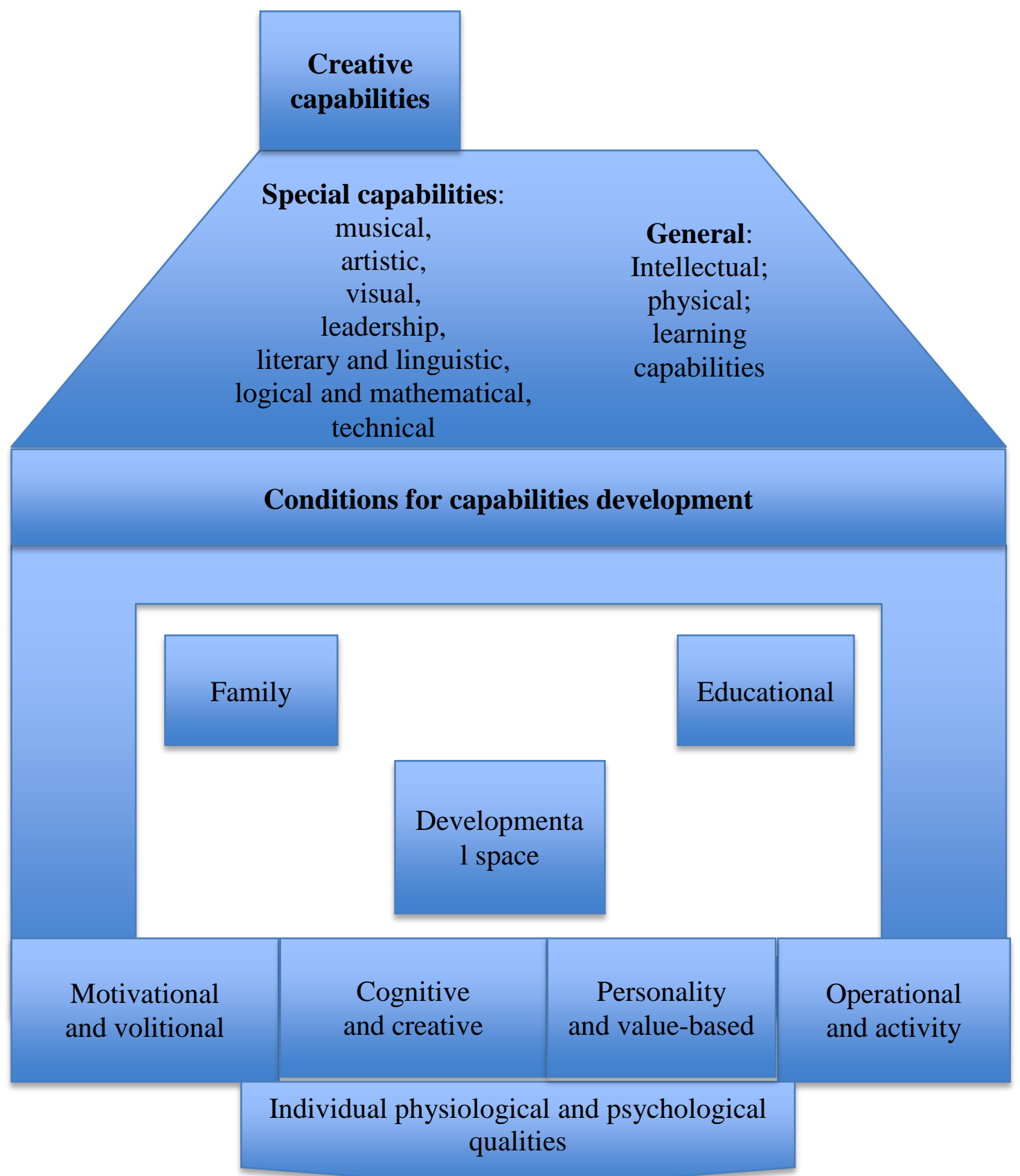

Fig. 1. Structural model of capabilities development 
Observing the success of children in a certain type of activity, adults can also notice the achievements that go beyond the age norms. They themselves are an indicator of giftedness. If a child is very pleased to engage in a certain type of activity and is almost indifferent to others, we can state that she has certain capabilities.

General intellectual abilities are manifested in the ease of learning, observation, acumen, mobility, speed of thinking, exceptional memory, rich and diverse awareness of the child. An intellectually gifted child thinks well, thinks clearly, asks many questions, is observant, has a creative perception and quickly responds to everything new.

Language skills are manifested in the child's unusual interest in reading, which becomes a favourite activity, in preserving and lasting attention to the book, verbal information, a good understanding of what the child is reading, memorizing and reproducing the read.

The capabilities in mathematics are manifested in the interest in calculating, measuring or organizing objects, in an unusual understanding of mathematical symbols for their age; the capabilities in natural science in an exceptional interest in the living nature, natural phenomena, inclination to their classification, in the interest in natural experiments, in understanding causal relationships in nature, and the like.

Communication and leadership are characterized by a high level of communication, easy adaptation to different situations. In front of strangers, the child retains self-confidence, easily communicates with adults and children, generates ideas and takes initiative. The child often becomes a leader in joint activities, assumes the role of organizer, and has the gift of conviction. Other children contact him or her for help or advice.

The artistic and visual capabilities of the child are manifested in interest in visual information. He remembers what he saw in detail. He draws and sculpts a lot of time, is working intensely on his works, and originally uses materials of artistic expressiveness. Building the composition of a drawing, he includes many details in it. There is no monotony in the images of an artistically gifted child; he reproduces in visual activity everything that he sees around.

Psychomotor capabilities are manifested in high interest in activities that require effort of fine motor skills. The child has good visual-motor coordination, loves to run, jump, has excellent balance when performing 
movements, exercises control over his body in any manoeuvring, has considerable physical strength in relation to his age.

If a child has an interest in music, singing, he is sensitive to the nature and mood of the music, composes his own original tunes or sings - he has musical capabilities and they are worth developing.

The child manifests independence and nonconformity, inventiveness in his productive activities, considerable flexibility in solving problems or using materials, can produce original ideas and find a new approach in standard situations, is interested in different mechanisms and machines, designs and projects a lot - he or she has the potential of technical creativity.

A child may be inclined to fantasize when he or she talks about something familiar, originally conveys the character, feelings, mood of the characters, easily builds storylines and prefers reading - then he or she is prone to literary creativity.

Children with artistic capabilities are easily involved in the role of any character, convey feelings and emotions through facial expressions, gestures, movements and like dramatization games ${ }^{7}$.

It is worth noting that the pace, ease of assimilation and the speed of advancement in a particular area can serve as a significant indicator of the development of capabilities. But it is necessary to take into account the results or the speed of development in relation to its conditions, because the same achievements in study or activity under different conditions may indicate unequal capabilities. The ability to achieve great achievements under externally difficult, disadvantageous conditions indicates particularly great capabilities.

In addition, it is important to analyse the creative potential of the child, which is an internal prerequisite for the development of capabilities, the core of talent. Creative potential includes:

- makings, inclinations, which are manifested in hypersensitivity, given selectivity, preferences, as well as in the dynamics of psychological processes;

- interests, their orientation, frequency and systematic manifestations, dominance of cognitive interests;

- curiosity, desire to create new things, inclination to solve and find problems;

\footnotetext{
${ }^{7}$ Bila I.M. Psychology of children's creativity / I.M. Bila. - Kyiv., Phoenix, 2014. - 200 p.
} 
- speed of assimilation of new information, creation of associative arrays, inclination to constant comparisons, development of standards for subsequent selection of information;

- displays of general intelligence - understanding, speed of assessment, choice of ways of solution, adequacy of actions;

- emotional coloration of the cognition processes;

- emotional attitude, influence of feelings on the process of subjective evaluation;

- persistence, commitment, determination, hard work, systematicity in work, courage in decision-making;

- creativeness - the ability to combine, find analogues, reconstruct, an inclination to options replacement, cost-effectiveness of decisions, rational use of means, time, etc.;

- intuitivism - the ability to quick assessments, decisions, forecasts;

- an inclination to build personal strategies and tactics when solving general and special new problems, tasks, finding a way out of complex, non-standard situations, etc. ${ }^{8}$.

An effective diagnostic tool in determining subjective inclinations in both childhood and adulthood is also a whole battery of projective techniques that have common properties. It is believed that when operating with uncertain material (for example, obscure pictures, or ink spots of a vague configuration, as in the Rorschach test), the subject projects the features of his inner world onto it. Having received the task to arbitrarily draw geometric shapes, draw a picture, etc., the child offers exactly the option that testifies to the features of his or her personal composition.

An efficient method of studying abilities and interests, starting from the senior preschool age, is self-analysis, introspection. In assessing the results of his activities, the child analyses his interests and abilities, determines the scope of major achievements, personal accomplishments and successes.

As for the factors that stimulate the formation of capabilities at the beginning of ontogenesis, primarily they are the following: providing a favourable atmosphere, a positive psychological climate, opportunities for exercise and practice; aesthetics of the developing environment; enrichment of the environment with a variety of new objects and

\footnotetext{
${ }^{8}$ Bila I.M. Psychology of children's creativity / I.M. Bila. - Kyiv., Phoenix, 2014. - 200 p.
} 
incentives; attracting literature and art which contributes to the formation of aesthetic criteria for a gifted personality; the wide use of divergent type questions, encouraging the expression of original ideas; refusal to express evaluations and criticism of the child; personal example of creative adult behaviour; the interaction of all participants in the pedagogical process; pedagogical skills of an adult in identifying and developing the abilities of a child. We will analyse in more detail the prerequisites for the formation of the capabilities in the next paragraph.

At the moment it should be borne in mind that the perception of a child by adults can be distorted by emotional factors, ignorance of age norms of development, incorrect evidence received from friends or even specialists. Taking into account the lack of operational and universal means of verifying the authenticity of life observations, the experimenter has to compare them with other objectively established data (test results, questionnaires, products of children's creativity, specialists' verified information, etc.) and the results obtained by the methodology proposed by us.

In the preparation of diagnostic tools, methods of studying the children's capabilities, we took into account the structural model of capabilities development designed by us (Fig. 1) and modified according to it the scale of rating of the capabilities basic characteristics of J.Renzulli, existing in experimental practice. We compiled the scales of the basic characteristics of the methodology for studying the capabilities of children in such a way that an adult raising a child could evaluate the characteristics that we highlighted in cognitive, motivational and volitional, creative, personal-value and operational areas in points from 1 to 4 . It is important to determine each of the points on the scale without reference to other points. The assessment should reflect how often adults observe in a child the manifestation of each of the characteristics. The assessments on different scales are not added up.

The study instructions were formulated, namely: "Read carefully the statement and put $\mathrm{X}$ in the appropriate place according to the following criteria: 1 - if you almost never observed this characteristic in a child; 2 - if you observe this characteristic from time to time; 3 - if you observe this characteristic quite often; 4 - if you constantly observe this characteristic".

The scales highlighted according to the model, include the following characteristics: 


\section{Scale I. Cognitive characteristics:}

- has an unusually large vocabulary for his age, uses terms with comprehension, language is distinct, easy and complex;

- has an extensive stock of information on a variety of topics (which go beyond the ordinary interests of children of this age);

- quickly memorizes and reproduces factual information;

- easily assimilates causal relationships; trying to understand "how" and "why"; asks a lot of questions stimulating the thought (as opposed to questions aimed at obtaining facts); wants to know what underlies the phenomena and behaviour of people;

- a sensitive and quick-witted observer; usually "sees more" or interprets more broadly what he sees, sees, reads and what happens compared to others.

\section{Scale II. Motivational and volitional characteristics:}

- demonstrates enthusiasm and activity;

- manifests good organization and diligence in the process of his favourite activities;

- feels confident in the area of his interests;

- brings his favourite business to an end;

- shows leadership abilities in the field of his competence. With pleasure shares with others what he knows and can do.

\section{Scale III. Personality and value-based characteristics:}

- consciously chooses the field of activity, cognition or personal relationships;

- demonstrates a selective preference for certain sides of reality, a certain content, a way of performing experimental tasks, and his attitude towards them;

- realizes himself, his qualities, how they are judged by others, his evaluations of others, the areas of the reality and the preferred activities;

- immersed in the situation, captured by it and leans on its previous experience;

- expresses confidently his thoughts, beliefs, interests and puts them into practice.

\section{Scale IV. Creative characteristics:}

- puts forward a large number of ideas or solutions to problems and answers to questions; offers unusual, original, reasonable answers;

- expresses fine sense of humour and sees humour in situations that don't seem ridiculous to others; 
- inclination to play with ideas; fantasizes, imagines: I wonder what happens if...; engaged in the adaptation, refinement and alteration of objects and systems;

- extremely sensitive to internal impulses and more open to the irrational in himself;

- sensitive to beauty, paying attention to the aesthetic component, is interested in details. He or she is not afraid to be different than everyone.

\section{Scale V. Operational characteristics:}

- has experience and knowledge in the chosen field;

- performs special tasks faster than others;

- acts confidently and carefully;

- strives for excellence in the field of his interests;

- masterfully possesses practical skills of favourite activity.

After evaluating each of the characteristics, it is necessary to calculate the total number for each of the columns, multiply by the corresponding number (score) and add the numbers obtained. The general indicator shows the rating, degree of manifestation, level of development of one or another characteristic of the child's capabilities.

Let us emphasize that the study of the characteristics of children's capabilities does not only diagnose the maturity of their basic components, but also focuses on their growth. In general, the capabilities identification procedure involves a qualitative analysis of all areas of a child's activities and should take the form of psychological and pedagogical monitoring (observation, analysis of activity products, keeping a diary, the use of projective methodologies, expert assessment methods, the scale of rating of a child's abilities basic characteristics, questionnaires for parents and etc.).

Studying the capabilities of children, it is advisable to rely on the principle of humanity, individuality and the "presumption of giftedness". We emphasize that the proposed diagnostic procedure, which includes analysis methods, meets all the requirements of psychological practice and creates opportunities for a thorough study of the ontogenesis of capabilities, their foundations, starting from childhood.

\section{Prerequisites for becoming a creative personality in a developing space}

The development of intellectual and creative potentialities of children is an important characteristic of preschool, primary school age, a period of intense and independent creativity of children. All this happens naturally 
and spontaneously, but it is important to find out the most important conditions for talent formation. As a rule, gifted children do not need targeted interventions, influences and formations, and all because "to teach an intelligent one is only to harm". According to scientists, education should come out of the natural organic development of truth from the primitive consciousness of the child; it should not give ready-made truths obtained by mankind, but develop his or her own truth.

For a long time in the countries of the West and East, the testing of intellectual abilities and other types of talents was admired. The society hoped that with the help of the data obtained it would be possible to identify gifted children early and with the help of special programs and well-trained teachers to "grow up" geniuses and talented people. A decade later, it became clear that nothing would come of it. For example, several generations of Japanese were selected in childhood by the criterion of giftedness for elite education, but none of them, admittedly, became a talented adult. Conversely, almost all known talents in childhood were often outcasts.

The data of the Japanese researchers are supported by examples from the lives of famous people from different countries. Vitaliy Bianchi, a well-known children's writer having hardly reached the upper classes of the classical gymnasium at the Institute of History and Philosophy, completely refused to study. His father had to transfer the boy to a private gymnasium, where he became interested in literature, but still ignored mathematics, sitting at the last desk and writing poetry. France's most famous man, named "Man № 1, ocean explorer of the twentieth century", Jean-Yves Cousteau, was expelled from school for breaking multiple windows. This did not prevent him from becoming a talented oceanographer, scientist and writer. O.V. Suvorov's parents did not even think that their son, who was lagging behind in physical development and was a sick boy, could become a military man. And it was out of question that a prominent commander could grow out of him ${ }^{9}$.

Scientists agree that intelligence, creative capabilities are determined by heredity no more than for 30-50\%. In most examples of a talent development, it is difficult to separate the heredity factor from early training. It is clear that children with signs of giftedness in the family are

\footnotetext{
${ }^{9}$ Lobodina S.V. How to develop a child's capabilities / S.V. Lobodina - St. Petersburg: Glagol dobro, Azbuka-Atikus, 2011. -320 p.
} 
constantly in a specific environment, they are more sensitive to influences that ensure their achievement in a particular area, and contribute to the effective assimilation of knowledge and skills. For example, a child born in a family of professional musicians hears music as early as in the womb, and this contributes to the development of his or her ability to recognize the pitch and rhythm.

According to many researchers, inborn capabilities are often discussed when adults show their helplessness, or pedagogical methods demonstrate their inefficiency. And yet external factors are determining, including, in addition to pedagogical systems and educational level, a family welfare, living conditions and lifestyle, social and economic conditions in the state, and even its historical heritage. That is, mental development is affected even by poor nutrition. After all, the baby brain is an organ that absorbs almost $90 \%$ of the energy in the body of a new-born, $50 \%$ - in a five-yearold child. And if this energy is taken away by some circumstance, it can have dire consequences. Even elementary iodine deficiency, as scientists estimate, lowers IQ by 12 points.

However, no child is born a genius or a fool. It all depends on the stimulation and the degree of brain development in the crucial, sensitive years of the child's life, when the adult's particular attitude to the child's creative activity may develop or slow it. Scientists prove that almost 50\% of mental capabilities are formed in a child under four years old, $80 \%$ - up to eight. "The age from birth to 6-7 years is the period when the fate of the child is decided", said Japanese violinist and teacher Sh. Suzuki. It is at an early age, depending on the conditions; the child's capabilities can be fully manifested or only marked out ${ }^{10}$.

If a child is brought up in an environment that is alien to his nature, then he has little chance to fully and completely develop in the future. In this case, it is important to what extent the opportunities of the society are consistent with the potential of the child.

Majestic pine trees that grow in the forest can serve as an example. They are not at all like their dwarf counterparts, who aspire to stay on rocky areas where there is practically no land, or their relatives, who were raised in pots by the Japanese craftsmen, regularly pruning their roots and preventing plants from getting proper nutrition. They look so much like an unfortunate Chinese princess's foot which at the age of five years is put in

\footnotetext{
${ }^{10}$ Ibuka M. After three it is already late / Masaru Ibuka. - M.: Olta, 2003. - 64 p.
} 
a block to keep a small shoe size. In all these cases, the change in form is not the result of genetic changes, but the hostility of the environment to the perception of this genotype.

The inborn inclinations of a child can be realized only in the active life of the individual, in a favourable environment, under the influence of proper education and training. Unfortunately, an artistically gifted child from the Central African tribe will never become an artist, just because he will not get paints in his hands with which he could designate his inner world [8].

Children are born with powerful individual creative potential, a resource of creative possibilities, the ability to creative actions, the ability to create. Already at a fairly early age, they also have a formed system of self-regulation, which, to a greater extent, is controlled by intuition. In the preservation of childhood and children's intuition P.A. Florenskyi saw the secret of human genius. The main task in this case should be the development of the internal cognitive and personal potential of the coming generation.

Nevertheless, in practice regrettably happens something that JeanJacques Rousseau wrote about: "Everything good which proceeds from the hands of the Creator of things, is degenerated in the hands of man. He makes the earth produce the products of another earth, a tree - produce the fruits of another tree..., he distorts everything; he loves ugliness; he does not want anything as it was created by nature, even a human; he wants to break him in, like a riding horse, to distort for fashion, like a tree in his garden"11.

In real conditions, adults impose their interests on children, preventing them from full demonstration of their capabilities, and they also lack pedagogical insight and predictability for discerning even vague outlines of future talent.

An unsuccessful example of the implementation of capabilities is described by Mark Twain. "... A man, once in the afterlife, asks to show him the best commander of all times. A great military genius, he writes, in our world was a mason named Jones. Wherever he appeared, the crowd immediately came together to look at him at least with one eye. Caesar, Hannibal, Alexander and Napoleon - all serve under his leadership, and, in addition to them, many illustrious commanders; but the people pay no attention to them when they see Jones. Everyone knows that if Jones had presented himself with a good chance, he would have demonstrated to the

\footnotetext{
${ }^{11}$ Russo J.-J. Selected writings / J.-J. Russo. - Moscow: Children's literature, 1976. - 187 p.
} 
world such talents of the commander that all the others would have seemed childish fun. But the case did not happen. Many times he tried to enlist in the army as a common soldier, the recruiting sergeant did not take him"12.

Unfortunately, such examples are not uncommon in life. A child needs an adult who is ready to see individuality, a creative personality in him and give him a violin or a brush, support the initiative, approve originality. The social factor of the development of the child's capabilities is considered to have the same significance as the factor of heredity and can fully compensate or, on the contrary, level its effect. If, for example, a new-born baby is raised in an environment that is alien to his nature, then he has no chance to fully develop in the future. The most striking example is the story of the "wolf girls" of Amala and Kamala, found in a cave near Calcutta. A lot of effort was made to restore the children's human appearance, but they were in vain. There are many examples like this. For example, in the novel "Doctor Zhivago" by B.Pasternak the daughter the main characters - incredibly gifted people - is brought up outside their influence, and as a result she does not have her parents' qualities. Therefore, it is important to remember that the child's inborn inclinations can be realized only in the active life of the individual, in a favourable environment, under the influence of proper education and upbringing ${ }^{13}$.

The attention of parents and adults is usually confined not to the talents and abilities of children in need of encouragement, but to their weaknesses, which they begin to develop to the middle level. It is reminiscent of the story of animals who decided to create a school where they were taught to fly, run, swim, dig and climb. They could not agree which subject was the most important, so they decided that the training program would be the same for everyone. The rabbit was unsurpassed in running, but he almost drowned at a swimming lesson. This struck him so much that since then he could no longer run. The eagle, of course, flew fantastically, but when he had to dig and ditch, he did not succeed, and he was sent to the class for skills correction and fixing. It took him so long that he soon unlearned to fly. The same thing happened with other animals. Now they have lost the ability to be skilled in their field and were forced to engage in activities that were unnatural to them ${ }^{14}$. The same thing happens with children when adults neglect their interests, talents and inclinations.

\footnotetext{
${ }^{12}$ Twain M. Collected Works: in 12 volumes / M. Twain - M., 1961. - Volume 11. - p. 407-409.

${ }^{13}$ Nikolayeva E.I. Psychology of children's creativity / E.I. Nikolayeva. St. Petersburg: Rech, 2006. -220 p.

14 Amstrong Thomas. Individual approach. How to grow and develop the mental abilities of your child independently / Thomas Amstrong. - Kharkov: Book club "Family Leisure Club", 2001. - 288 p.
} 
A. Saint Exupery in his famous work "The Little Prince" also writes about this: "Adults advised me not to draw, but to be more interested in geography, history, arithmetic. And so it happened that at the age of six I refused from the genius career of an artist and lost faith in myself ${ }^{\prime 15}$. Considering the above, an important slogan in working with children there will be not only the psychologist's rule: "Do no harm!", but also the biblical commandment: "Do not kill (inclinations, capabilities, what is given by nature)!"

Special and popular literature describes many cases in which a child did not show interest in studying mathematics, physics, or chemistry, and was ranked among the "lazy", "unpromising", and even "dumb" ones. But this same child, being carried away by the design of automobiles, radio devices, computer equipment or other creativity, began to feel the need to study these sciences - and not by force, but independently and eagerly studied the same chemistry, physics or mathematics ${ }^{16}$.

The development of various functional systems of a gifted child proceeds unevenly, at each age stage, some functions look more active and formed, and some are in secondary places. But time passes, and in the next age periods they are ahead of other functions, yesterday's outsiders "go ahead". Different functional systems at different ages demonstrate different degrees of maturity and perfection of the individual. Some have already formed and will only be modified in the future, while others are at the stage of active formation ${ }^{17}$.

Asynchrony in the development of capable children is quite common. It may seem that to a small child inherent are the characteristics which are inherent to several age periods at once. According to the psychologist's figurative description, a child can be eight-year-old when riding a bicycle, twelve-year-old when playing chess, fifteen-year-old when studying algebra, ten-year-old when collecting fossils and two-year-old when sharing sweets with a sister.

Children often have outstanding capabilities or talents, but at the same time show low capabilities or even incapabilities for certain aspects of learning. So, for example, in some famous people (Leonardo da Vinci,

\footnotetext{
${ }^{15}$ Antoine de Saint-Exupery. The Little Prince / Antoine de Saint-Encupery; translated from French - M.: Publishing house "Sofia", 2004. - 144 p.

${ }^{16}$ Scheblanova E.I. Unsuccessful gifted schoolchildren / E.I. Shcheblanova. - M.: BINOM. Laboratory of Knowledge, 2011. -245 p.

${ }^{17}$ Scheblanova E.I. Unsuccessful gifted schoolchildren / E.I. Shcheblanova. - M.: BINOM. Laboratory of Knowledge, 2011. -245 p.
} 
A. Einstein) dyslexia (impaired reading skills) was one of the symptoms of very high levels of visual thinking, which develops before writing occurs and is more significant and valuable than verbal intellect ${ }^{18}$.

A pedagogical effect that is premature or belated in relation to a certain period is not effective enough and adversely affects the development of personal qualities. For example, you can try to start teaching the academic drawing to a pre-schooler, but no one has succeeded in achieving significant results in this - the perceptual, analytical abilities of a child are not developed enough for this yet. And it's a completely different matter of teaching this difficult thing for teenagers. The child's capabilities are revealed as he climbs the steps of constantly changing interests and inclinations. And the more such steps a child passes, the richer and more multiple personality the person becomes as a result.

Outstanding achievements are just one of the hallmarks of childhood talent and do not guarantee creative achievements in adulthood. Talent development can be delayed and even suppressed at any age stage. For example, in the first years of a child's life, the sensitivity and intuitiveness of the right hemisphere is maintained and developed quite successfully in the family and in kindergarten. But, the closer the child's age approaches 7 years, the more attention is paid to the development of the left hemisphere (every day the amount of time allotted for singing, listening to music, dancing and sports, modelling and drawing is reduced - they are supplanted by classes in numeracy, reading and writing). From the first year of study, $90 \%$ of school time is devoted to subjects aimed at developing the left hemisphere! And as a result, artistically gifted children experience the greatest discomfort at school. The more logically and consistently the new material is explained, the more difficult it is for them to learn it.

In addition, a significant number of children do not show their abilities and capabilities in the existing education system, built mainly according to the age principle. The abilities of such children are usually called hidden, generated by a complex interweaving of various internal and external causes that impede the realization of the high potential of children in their achievements. By putting the stigma of the "ungifted" child, whose abilities are not clearly manifested, adults can kill his confidence in himself.

\footnotetext{
${ }^{18}$ Scheblanova E.I. Unsuccessful gifted schoolchildren / E.I. Shcheblanova. - M.: BINOM. Laboratory of Knowledge, 2011. - 245 p.
} 
The "ugly duckling effect" can be described as a situation where objectively valuable qualities that make it possible to achieve outstanding success in life are perceived as flaws in the early stages of personality development and cause a conflict between a gifted child and his environment. A similar thing happens in real life, parents and teachers do not pay due attention to the subtle movements of the child's soul, they lack knowledge, because of prejudice, they don't notice the outstanding potential opportunities of the child ${ }^{19}$.

Also, there are cases when minor achievements of the child are perceived by adults as a gift. Sometimes incorrectly chosen educational strategies form in a gifted child an overestimated self-esteem, while ignoring the development of his volitional efforts and other character traits important for the development of genius. And as a result, the child does not pass the trial by talent and it gradually dies. It is important to form the child's objective self-esteem, the ability to evaluate himself, his actions and the actions of others.

An interesting example of the positive influence of parental attitudes is described by French author R.Gary in the autobiographical novel "Promise at Dawn". His mother emigrated from Russia, where she was an actress. In a foreign land, she did not even try to return to her beloved profession and earned money with hard work to give education to her son. Her only consolation was the dream that her son would reach all the heights in society that are possible in France (which is now almost impossible for those born in France). She did not cease to inspire her son and speak to everyone with whom she spoke: "My son will be the French ambassador, gentleman of the Legion of Honour!" He will dress in London."

Further, the author writes: "Until now, I distinctly hear rude laughter and blush when I write these lines. I see mocking, angry, contemptuous faces - I see without hatred: these are only human faces, a common thing. Perhaps it is better to say at once for the sake of clarity that today I am the Consul General of France, a party to the Liberation, the Cavalier of the Legion of Honour. And there is no doubt: I dress in London. I cannot stand the English cut, but I have no choice",20.

\footnotetext{
${ }^{19}$ Scheblanova E.I. Unsuccessful gifted schoolchildren / E.I. Shcheblanova. - M.: BINOM. Laboratory of Knowledge, 2011. - 245 p.

${ }^{20}$ Gary R. Promise at Dawn / Romain Gary. - M.: Azbuka, 2007. - 352 p.
} 
And vice versa, unreasonable, degrading criticism and negative attitudes ("You're lump, slut, etc."), comparison of a child with other children form alarming and aggressive tendencies in his behaviour, which can be manifested in the future too. In general, scientists call various reasons that impede the realization of the children's potential. Among them are environmental factors:

- the family has very low, too variable, too rigid expectations;

- chronic absence or lack of stimulation, delayed training or vice versa training according to the program of a higher (corresponding to capabilities) difficulty level;

- the peer pressure which requires compliance with "ordinary" standards, "to be like others";

- loneliness, neglect by peers and an educational establishment.

\section{Individual factors:}

- internalized problems: depression, anxiety, perfectionism, avoidance of failure, low self-confidence;

- externalized problems: disobedience, irritability, nonconformity;

- impaired learning capabilities that are laid on performance;

- non-traditional types of capabilities that do not meet the expectations of teachers;

- defect of self-regulation: disorganization, impulsivity, attention deficit, etc.

Among objective reasons, they also incude: a low psychological level of preparation of teachers for working with children who show nonstandard behaviour and thinking; the absence of special programs, special courses at the university to prepare students for working with gifted children; it is common among adults that a gifted child does not need help; the absence of specific programs, technologies for working with gifted children; the deficit of psychological knowledge among adults about the individual and personality characteristics of the gifted children's behaviour and development (and they just have many personality problems in relations with adults and peers), etc.

All this again emphasizes the need for a unique strategy of pedagogical behaviour of adults and the necessity for humanistic technologies for working with children.

For the realization of the inherent potential of a child, joint creative activity with adults is especially important. At this time, the child seeks to 
imitate a significant adult, as a creative model, which is a prerequisite for the formation of his creativity. Getting into a new situation, he reproduces the ready method of action, repeats it after the adult in order to achieve the desired result. Subsequently, the imitation of the child becomes creative, he shows elements of novelty and self-activity, gets acquainted with various options for the implementation of innovative activities, determines his advantages in accordance with his own inclinations and skills without making significant changes. All this happens under the conditions of the "child-adult" commonness, a personality-oriented model of education, which is characterized by the following features:

- the adult in communication with children adheres to the provisions "not near, not over, but together":

- the adult's goal is to contribute to the formation of the child as a person. The adult's task: to ensure a sense of psychological security, the child's confidence in the world, the joy of existence, the formation of the foundations of the personality (the basis of personality culture), the development of the child's individuality;

- communication methods - understanding, recognition and acceptance of a child's personality, based on the ability to take a child's position which are formed in adults, taking into account his point of view and not ignoring his feelings and emotions;

- tactics of communication - cooperation;

- the adult's position - to take into consideration the interests of the child and the prospects of his further development as a full member of society;

- the view of a child as a full partner in the conditions of cooperation $^{21}$.

The participation in joint activities allows you to create those necessary conditions in which the child will not only receive knowledge from an adult, but also will develop his potential creative and cognitive abilities in conditions of interaction with him. It is the future unique picture of the world, created by the baby's own efforts, that forms the basis of his creative activity.

Creativity is stimulated by psychological safety, unconditional acceptance of the child's personality, his unconditional love. Unconditional

\footnotetext{
${ }^{21}$ Bila I.M. Psychology of children's creativity / I.M. Bila. - Kyiv., Phoenix, 2014. - 200 p.
} 
love, primarily of a loving mother, provides for the acceptance of a child regardless of his merits or demerits and is manifested in all sincere relationships. Unconditional love is an important condition that can ensure the full realization of the child's potential capabilities and talents. It is important for an adult not to interfere with a child's creation, to be near him in this process, to accept and understand his position, to be creative himself. It is important to turn to the child's natural ability to create, support, create favourable conditions for its manifestation and stimulate the children's desire to manifest originality.

A guideline in the selection by adults of adequate means of developing, educational and training impacts on a person is his age and individual life experience. It is worth dosing, repeating, varying creative tasks, taking into account the level of mental development, the abilities of each child, being in advance of children's plans, going a little ahead: what a child can do at the first stage with some help from an adult, later he can already do himself (according to L.S. Vygotskyi). This determines the change in emphasis from the analysis which is typical for most children of a certain age, to the search for the individual, special, unique one. It also broadens the adult's understanding of the possible manifestation of creative behaviour by a pre-schooler, and makes it possible to optimize his individual creative trends.

\section{CONCLUSIONS}

Childhood is a period of inexhaustible opportunities for development and growth of individual abilities and talents. It is important to cultivate in the child his essential powers, individual identity and uniqueness, to activate the mechanisms of self-development and creativity. Our structural model of studying, development of capabilities and awareness of adults, raising children, about the specifics and consistent patterns of their manifestation will help to accelerate the success of the growth of capabilities, the formation of a creative, harmonious personality in preschool age. In the course of the analysis of scientific researches, bibliographic data, we have found out the prerequisites of becoming a creative personality in the developmental space, the factors that stimulate the manifestation of capabilities at the initial stage of ontogeny within the proposed model of capabilities development. 


\section{SUMMARY}

A detailed analysis of the problem of capabilities allowed us to build a structural model of the development of children's capabilities, which takes into account the integrative, multidimensional structure of capabilities and the laws of their ontogenesis which are manifested in the individual characteristics of the course of mental processes (attention, perception, imagination, thinking, memory) and personality formations (orientation, emotional and value-based, volitional elements) in certain types of activities. This model lays the basis of the diagnostic tools developed by us, the methodology of studying the children's capabilities, the scale of rating the basic characteristics of capabilities.

A number of favourable prerequisites and factors of formation and flourishing of capabilities in childhood have been found out, the reasons that impede the realization of the children's creative potential have been analysed.

\section{REFERENCES}

1. Amstrong Thomas. Individual approach. How to grow and develop the mental abilities of your child independently. / Thomas Amstrong. Kharkov: Book club "Family Leisure Club", 2001. - 288 p.

2. Antoine de Saint-Exupery. The Little Prince / Antoine de SaintEncupery; translated from French - M.: Publishing house "Sofia", 2004. $144 \mathrm{p}$.

3. Bila I.M. Psychology of children's creativity / I.M. Bila. - Kyiv., Phoenix, 2014. - 200 p. $352 \mathrm{p}$.

4. Gary R. Promise at Dawn / Romain Gary. - M.: Azbuka, 2007. -

5. Ibuka M. After three it is already late / Masaru Ibuka. - M.: Olta, 2003. $-64 \mathrm{p}$.

6. Lobodina S.V. How to develop a child's capabilities / S.V. Lobodina. - St. Petersburg: Glagol dobro, Azbuka-Atikus, 2011. $320 \mathrm{p}$.

7. Losyeva A. A. Psychological diagnosis of giftedness: a textbook for high schools / A.A. Losyeva. - M.: Academic Project: Triksta, 2004. $176 \mathrm{p}$. - (The manual of a practical psychologist).

8. Nikolayeva E.I. Psychology of children's creativity E.I. Nikolayeva. St. Petersburg: Rech, 2006. -220 p. 
9. Gifted children: translation from English / edited by G.V. Burmenskaya and V.M. Slutskiy. - M.: Progress, 1991. - 376 p.

10. Platonov K.K. Problems of capabilities / K.K. Platonov. - M., Nauka, 1972. -312 p.

11. Rubinstein S.L. The problem of capabilities and questions of psychological theory // Psychology of individual differences / ed. by Yu.B. Gippenreiter, V.Ya. Romanova. - 3-rd ed., revised and accomplished. - M.: AST: Astrel, 2008. - P. 47-54. - (Reading book on psychology).

12. Russo J.-J. Selected writings / J.-J. Russo. - Moscow: Children's literature, 1976. - $187 \mathrm{p}$.

13. Savenkov A.I. The psychology of children's giftedness / A.I. Savenkov. - M.: Genesis, 2010. -440 p.

14. Subbotskiy S.V. The child opens the world / S.V. Subbotskiy M.: Prosveshcheniye, 1991. -207 p.

15. Twain M. Collected Works: in 12 volumes / M. Twain - M., 1961. - Volume 11. - P. 407-409.

16. Shadrikov V.D. Psychology of capabilities // Psychology of individual differences / ed. by Yu.B. Gippenreiter, V.Ya. Romanova. 3-rd ed., revised. and accomplished. - M.: AST: Astrel, 2008. P. 64-79. - (Reading book on Psychology).

17. Scheblanova E.I. Unsuccessful gifted schoolchildren / E.I. Shcheblanova. - M.: BINOM. Laboratory of Knowledge, 2011. -245 p.

\section{Information about the authors:}

Bila I. N.

Candidate of Psychological Sciences, Associate Professor at the Department of Psychology and Pedagogy of the V. I. Vernadsky Taurida National University 33, Ivana Kydri str., Kyiv, 01042, Ukraine 